\title{
Chapter 1 \\ The Anthropology of Suicide: Ethnography and the Tension of Agency
}

\author{
Daniel Münster and Ludek Broz ${ }^{1}$ \\ "Everyone dies ... \\ Very few people kill themselves" \\ Emile Durkheim 1952: 267
}

Suicide is a challenging object of study. As Ian Hacking has recently claimed, "[t]he meanings of suicide itself are so protean across time and space that it is not so clear that there is one thing, suicide" (2008: 1). For anthropology, the particular challenge lies in thinking beyond some of the assumptions implicit in the powerful and widespread clinical conceptualization of suicide, which presents it as a pathological and individual act, committed with willful intent, full consciousness and unambiguous authorship, whose default subject is arguably a "Western," male, white, middle-class human. These implicit assumptions serve as a "gold standard" of real suicide, to which all acts of self-harm are compared or ultimately attributed. In this volume, however, we aim at abandoning such assumptions in favor of nonEuropean experiences of self-harm in order to re-examine critically the Western tradition of thinking about suicide.

The ethnographies assembled in this volume engage with cultural practices of making sense of suicide, and in particular with the multitude of questions and answers about agency, personhood, and death that circulate within specific vernacular and expert regimes of knowledge around the issue of suicide. When families, neighbors, religious specialists, doctors, public health experts, activists, and newsmakers speculate about possible motives and reasons behind suicides, they operate with assumptions about free will, suffering, authorship, power and personhood and about "the very quality of life experienced by someone who chooses to die" (Marks 2003: 308). By recording and analyzing ethnographic instances of such sense-making, this volume seeks to highlight the ambivalent

1 The introduction has benefitted from insightful comments, suggestions, and criticisms by many people. We are particularly grateful to Katrina Jaworski and Jocelyn Chua for their critical readings of earlier drafts. Both editors have contributed equally to the writing of the introduction as well as to the editing of the book as a whole. The decision to put Broz's name as first editor of the volume and Münster's as first author of the introduction was arbitrary. 
position of agency in contemporary understandings of suicide. The focus is on rationalizations of suicide events - popular, expert and scientific - and how they articulate situated ideas about human personhood, the morality of death, and the human capacity to voice dissent and act politically through self-inflicted death.

In this opening chapter we develop our argument about the centrality of agency, personhood, and power for the anthropology of suicide by dealing first with the core premises of what we like to call the "mainstream" of suicide studies and the counter-hegemonic potential of the ethnographic approach. Second, we elaborate on what we identify as the central tension of agency in suicide by focusing on both scientific epistemologies and vernacular understandings of the phenomenon as manifested in the ethnographic record. Third, we discuss the challenge that the anthropological work on personhood poses for the Western Self implicit in suicide studies. Finally, we connect agency in suicide to the question of "power" by focusing, on the one hand, on ideas about the human capacity to performatively express dissent and to act politically through self-inflicted death and, on the other hand, on the diagnostic potential of suicide ethnography for the study of structural violence.

For numerous thinkers throughout history (notably philosophers), suicide has pointed to central questions about the human condition. As the existential philosopher Albert Camus claimed famously, "There is but one truly serious philosophical problem, and that is suicide" (1955: 3). Building on the centrality of suicide for Camus, anthropologists James Staples and Tom Widger argue that "[q]uestions of existence, survival, and coping ..., whether one agrees with Camus or not, are surely crucial for human beings everywhere, and go straight to the centre of anthropological enquiry" (Staples and Widger 2012: 185). Yet the potential significance of suicide for ethnographic understandings of the human condition stands in stark contrast to the relative silence on the subject within social and cultural anthropology as academic disciplines. In fact, anthropology has been a latecomer to the systematic study of suicide, leaving as yet little trace in suicide studies (for a review of some recent anthropological contributions, see Macdonald 2007; Staples and Widger 2012).

We argue that the reasons for the reluctance of social and cultural anthropology to afford greater attention to suicide are to be found in the epistemological and methodological challenge of studying suicide ethnographically. Anthropology has historically aimed at generalizing cultural forms (e.g. norms, types, structures, patterns) uncovered through long-term ethnographic engagements with everyday life contexts, thus focusing on regular and quotidian rather than the exceptional and contingent. However, in the context of a particular locality, suicides are contingent phenomena whose occurrence cannot be foreseen as only rarely do individuals actively and successfully seek to end their own lives. The average Suicide Mortality Rate (SMR) for "Western" countries suggests that for every 
ten persons who commit suicide in any given year, nearly a hundred thousand do not. ${ }^{2}$ And yet, despite - or because of - the exceptionality of suicide (Morrissey 2006: 1) that has largely prevented anthropology from a substantial ethnographic contribution to its study, there seems to be an impulse, among both researchers and the population at large, to make sense of suicide cases in relation to extrapersonal issues. Regardless of the statistical odds, most human societies tend to treat suicides not as idiosyncratic and exceptional ways of dying but as a kind of death indicative of larger, more significant issues, such as ruptures in social, economic, and moral life.

Suicidology has addressed the problem of exceptionality in two ways. One approach involves the use of what Nicolas Rose calls "psy knowledge, techniques, explanations, and experts" (2006: 12). Psy stands for "the psychosciences and disciplines psychology, psychiatry, and their cognates" (Rose 1998: 3), fields that have contributed to the medicalization and pathologization of suicide since the nineteenth century. From this perspective cases of suicide become integrated into a clinical picture and, in Ian Marsh's words, a "compulsory ontology of pathology" (Marsh 2010: 31). The second approach deals with the exceptionality of suicide through quantitative regimes of representation (cf. Hacking 1990). The disciplines that rely on statistical aggregation of large population numbers in the form of suicide rates (e.g. sociology, criminology, demography, and public health) also grew in the nineteenth century, this time out of the field of moral statistics which dealt with deviance and social problems. Both of these epistemic clusters offer particular solutions to the methodological problem of the rarity of suicide and provide implicit clues in the search for meaning in suicide: medicalization has rationalized suicide in terms of pathology, while quantification has demonstrated statistical correlations between suicide and other (national) indicators of health and well-being of populations.

These expert knowledge regimes on suicide entail a logical tension which we refer to as the tension of agency: the dialectic of agency and patiency. On the one hand, they build on a specific Western notion of agency and subjectivity by defining the object of study — suicide — as intentional, agentive action. This intentionality distinguishes suicide sharply from "normal ways of dying." On the other hand, these knowledge regimes partly deny agency (as free will) to the suicidal person by invoking allegedly universal causes that are beyond the individual's (conscious) control and possibly outside of their personhood altogether, such as depression, serotonin levels, gender, genetics, sexual orientation, or financial crises. This tension of agency, the simultaneous reliance on and denial of agency, sometimes comes with a dismissal of situated political and cultural meanings of self-destructive acts in suicidology.

2 See World Health Organization for national rates of suicide mortality (based on successful suicides per 100,000 persons per year) (http:/www.who.int/mental_health/ prevention/suicide_rates/en/index.html, accessed 12 November 2013). 
The tension of agency is not only built into medical and sociological suicidology but is also implicit in most vernacular discourses about suicide. The tension, the necessity and denial of agency, seems to us to be connected to the very widespread classification of suicides as a "bad death" (Seale and van der Geest 2004). Suicide, Parry and Bloch argue, is the "supreme example of bad death": the self-destruction of a person "is regarded with such incomparable horror" in many cultures because their "soul may forever be excluded from the society of the dead and must wander the earth as a lonely and malignant ghost, while the corpse may not be accorded the normal rites of disposal ..." (Bloch and Parry 1982: 16). The abnormality of and moral outrage surrounding suicide in turn require a clear ruling as to whether a particular case of death must be regarded as a suicide as opposed to a normal or "good" death. What makes most suicides "bad" deaths seems to be the agentive decision to end one's life, that is the will to die, or the act of giving in to the "death wish" as Freudians would call it (see Menninger 1938). In other words, there is no suicide without agency, or to be more precise, there is no suicide without intentionality. Almost universally - and across the registers of vernacular and expert knowledge - agency appears to be a fundamental component of suicide as bad death.

The centrality of agency in vernacular definitions of suicide thus stands in tension with equally widespread assumptions about victimhood or "patiency" (Schnepel 2009) in suicide, which hold that the act is caused by influence of agents, forces, or structures located outside the person, such as demons, kin relations, illness, or violence. Attempts at locating agency outside of the suicidal person have historically been important in deflecting moral or legal sanction away from the suicidal person or, as we prefer to call them, the suicidé. ${ }^{3}$ As historian Rab Houston points out, the growing popularity of legal and medical verdicts of "lacking wrongful intent" (non compos mentis) among forensic coroners after 1750 went hand in hand with a substitution of ideas of sinful blasphemy for medicalized explanations (Houston 2009).

Counter to extra-personal explanations for suicides are issues to be explained by suicide. Suicide events are often assumed to point toward broader social problems in the wider world. The questions they pose may then assume a political character. How, for example, should one make sense of the fact that more US soldiers have died from suicide than in combat since the war in Afghanistan began (Gibbs and Thompson 2012)? Does this fact tell us something about gender (masculinity), bureaucratic indifference, or institutional pressure in the military?

3 In this introduction we use the French word suicide to refer to the person committing/ attempting/contemplating suicide. This avoids the potential confusion of referring to both the (suicide) act and the (suicide) victim by the same term "suicide," as is common in the English language. More importantly, suicidé is grammatically a peculiar passive-active construction (like employee - an agent, but not quite as active as its counterpart, the employer). We therefore prefer the term over the commonly used "suicide victim" "suicide completer" and "suicide attempter," as each of these stresses only one aspect of the agency/patiency divide. 
Similarly, what is to be made of the news that suicide rates in Europe increased following the financial crisis or that, following the suicides of several people dispossessed of their homes, Spanish banks had to temporarily suspend evictions (Dowsett 2012)? What is to be learned from the study of these news reports about alienation, fear, and the structural violence of economic orders? From an anthropological perspective, the question can be formulated thus: How can we appreciate the diagnostic potential of suicide cases - their inherently accusatory nature and their seismographic detection of social dysfunctionality and structural violence-without, however, resorting to universalizing positivism that ignores context-specific understandings of the indictment expressed through suicide? The anthropology of suicide must acknowledge that the diagnostic potential of suicide cases is equally shaped by history and power.

The central challenge for an anthropology of suicide is to uncover and describe the peculiar tension of agency prevalent in specific ethnographic settings, including in their inhabitants' explanatory repertoire and in the explanatory repertoire of anthropology itself. This means making sense of agency and patiency in situated discourses and in expert knowledge regimes that come to bear on particular cases of self-destruction. With such focus, anthropology may be able to contribute novel perspective to medical and sociological suicidology, to which we turn next.

\section{Disciplining Suicide and the Challenge of Ethnography}

The secularization of suicide since the eighteenth century has replaced its theological conception as a mortal sin and abomination (Weaver and Wright 2009) and given rise to two major currents of European thought on the issue, which Anthony Giddens calls the "thèse psychiatrique" and the "thèse sociologique" (1977: 328). While the psychiatric thesis, or "psy" discourse as Ian Marsh (2010) — following Nicolas Rose (1998) - calls it, transformed suicide from sin to mental disease and thereby relocated it into the realm of medical sciences, the sociological thesis detached suicide from moral consideration at the individual level by treating suicide rates as quantitative indicators of social constraints on the individual. Although the two currents or scientific ontologies (psychiatric medical sciences, quantitative epidemiology and sociology) have general applicability, the topic of suicide was instrumental in their creation and consolidation. Consequently, suicide was "pathologized" at the individual level by medicalization and at the collective level by the removal of any moorings within individual contexts and by understanding suicide rates as social facts indexing large-scale social turbulences, social pathologies or "anomie" in Durkheim's classical formulation (1952: 201-39). These two currents of thought have shaped commonsense understandings of suicide worldwide and laid the foundations for suicide studies as a modern discipline.

Suicidology is a complex and well-established field (see Shneidman 2001) inhabiting the intersection of clinical psychology, public health, and quantitative sociology. Range and Leache's review (1998) of leading journals in suicidology 
acknowledges some of the discipline's major achievements, which include gathering impressive knowledge about risk factors in relation to age, gender, and mental health. Suicidology has refined classification algorithms for suicide, calculates probabilities and can provide statistics of suicidal ideation (talk of suicide) among certain at-risk groups or predict the prospects of medication and cognitive-behavioral therapy among suicidal clinical patients. Despite all this knowledge and an increasingly fine-grained vocabulary that distinguishes between suicide attempts, suicide ideation, acts of self-harm, and suicide mortality, suicide as a concept remains complicated. The idea of suicide in suicidology, Range and Leach argue, retains "philosophical roots in logical positivism and structural determinism" (1998: 24).

The authors in this volume share the view that anthropology, with its emphasis on ethnography, offers a valuable alternative to the predominantly applied research agendas of suicidology. Perhaps most importantly, anthropology as we understand it aims at a symmetrical treatment of expert and vernacular modes of making sense of suicides. In the domain of the "thèse psychiatrique," much of critical medical anthropology today destabilizes Eurocentric certainties surrounding the medical sciences' knowledge claims by bringing in questions of power, the geopolitics of knowledge, and divergent ontologies of body, personhood, health/well-being, and death. The growing interest in the anthropology of suicide more generally, to which this volume attests, is a catalyst for the "provincialization" of suicidology's taken-for-granted ideas about personhood or subjectivity.

In the domain of the "thèse sociologique," ethnography also adds a complementary perspective to statistical approaches. Many authors, most prominently perhaps sociologist Jack Douglas (1967: 167-210), have pointed to the methodological problems involved in the positivist production of and reliance on aggregate suicide data. These problems are well known and include the way coroners and police investigators are required to produce unambiguous results, the way legal implications, stigma, and shame may encourage community members to conceal suicides from the authorities, and the way national and transnational statistical organizations, such as national crime records bureaus or the World Health Organization, produce their data. However questionable the production of suicide statistics may be, ethnographers of suicide cannot afford not to take suicide statistics seriously. This is because modern suicide is entangled in a world of indicators: suicide statistics are social facts, not in the way Durkheim understood them, as seismic instruments that speak of the inner life of society, but in Paul Rabinow's sense that "representations are social facts" (1986). Anthropologists have not come to believe unquestioningly in the ontological foundations of statistical indicators; instead, they have begun to appreciate the performative power of science and state-produced representations of social problems. To put it another way, anthropology has made statistical representations and their effects on populations the object of ethnographic inquiry (e.g. Li 2007; Münster 2012).

The anthropological study of suicide must not be limited to producing intimate ethnographies of individual suicide cases. It would be a mistake to 
reduce the potential of ethnography in the study of suicide to the role of adding cultural context to an understanding of individual suicide cases. In other words, a turn to situated life histories and narratives of suicides is not a panacea for all methodological fallacies of statistical and psychological approaches to suicide. French anthropologist Charles Macdonald has pointed out that conventional ethnographic approaches are prone to what he calls "the case studies fallacy." By this he means the problem that the sequence of events and circumstances that is often singled out to explain a suicide case would be meaningless without the final act of self-harm: "Suppose now that the same case or sequence of events is told, but omitting the final $n+1$-then what? The whole case vanishes altogether as a suicide story, but it remains a perfectly plausible life story, perhaps sad, but not ending in death" (Macdonald 2007: 227). The case studies approach, employed in many classical ethnographies (Bohannan 1960; Firth 1961; Malinowski 1978) thus suffers from an inherent drive to explain suicide cases by the sequence of events preceding the suicide, while ignoring similar sequences that were not followed by suicide. In other words, the meaning ascribed to particular events in life is determined by viewing them retrospectively through the lens of suicide.

The ethnographies assembled in this volume (not all chapters are ethnographic; see Jaworski, Sharp and Linos) take a different route altogether. Their intention is neither to uncover the one interpretive key to unlock the meaning of suicide practices in society $\mathrm{X}$ nor to explain suicide rates with reference to transformations in society Y. Instead, the chapters collected here use ethnography to interrogate the boundaries of the category of suicide itself and to make important points about the discursive uses of suicide in everyday life. Given this, it is scarcely the aim of the authors to achieve an ethnographic proximity to suicide, in the sense of getting as close as possible in a temporal, spatial, or empathic sense to suicide acts. Rather, they study what may be called suicide fields - the wider domains of practices and of sense making, out of which realized, imaginary, or disputed suicides emerge. Instead of producing claims about the causality of suicide, which would compete with psychological or sociological accounts, the ethnographic approach substitutes analytical explanations of suicide(s) for the study of "popular discourse about causality" (Staples, this volume), the "moral talk about farmers' suicides" (Münster, this volume), children's suicide games (Widger, this volume), or "women's allusions to, jokes about, and fantasies of willful death" (Chua, this volume). Representations of real and imaginary suicide provide idioms through which ethnographers may engage in conversation about culturally specific notions of illfare and the good life. Although ethnographers may engage with suicide in order to speak about gender, youth, neoliberalism, or agrarian ecologies, among other things, the study of suicide is more than another arbitrary entry point for the anthropological study of social and cultural complexity. Suicide, as a way of "death making" (Chua, this volume) and as bad death, seems to offer unique opportunities for speaking about existential matters: life and death, justice and revenge, success and failure, power and resistance, personhood and individuality, agency and victimhood. 
Our enthusiasm about ethnographic approaches nevertheless should not be mistaken for anthropological complacency. Though the anthropology of suicide has sought to decenter Western ontologies, avoid the pathologizing psy-discourse and interrogate positivist frameworks of suicidology, it may not be able to resolve the tension of agency inherent to the "thèse psychiatrique" and the "thèse sociologique," either: ethnographers, like everyone else, simultaneously ask why the suicidé "did" it and who or what "made them do" it. In most ethnographic studies, suicides are treated both as indications of individual choices and pathologies and as diagnostics of larger structural constellations. What perhaps differentiates ethnographic studies of suicide from their counterparts in sociology and psychology is their symmetrical treatment of popular and authoritative knowledge about suicide. In the anthropology of suicide, scientific, administrative and legal representations about suicide become objects of investigation. ReyesFoster's chapter explores Mexican expert knowledge systems and vernacular modes of making sense of suicide in a single framework as commensurable and curiously entangled discourses. Münster's chapter discusses how the media hype around Indian farmers' suicides and the classification of a South Indian region as "suicide prone" by the developmental state feeds back into vernacular debates about suicide and possibly into suicidal practices. This looping effect is also pointed out by Tom Waidzunas, who, drawing on Ian Hacking, argues that the circulation of statistical representations of gay teen suicides has problematic effects on the identity formation of young gays (Waidzunas 2011).

The authors in this volume cannot and need not compete with the scientific methodologies and epistemologies of suicidology. Instead of struggling to define suicide or to explain its positive correlation to neurobiological, genetic, or socialstructural properties, the ethnographies assembled here largely seek to explore the fuzzy edges of the concept of suicide and the practices of self-destruction. Instead of starting off from a definition of the core concept, which would be dependent on modernist dichotomies and implicit notions of agency and personhood, many authors in this volume approach suicide and agency via phenomena that may or may not fall under the rubric of suicide "proper." Flora's Greenlandic ethnography critiques Durkheimian understandings of suicide by focusing its ethnographic lenses on walking into the wilderness, another form of willful death, or rather, as Flora would put it, another form of self-detachment, known locally as qivittoq. Chua's, Staples's and Widger's ethnographies explore the fine line between suicide and what suicidologists would call "suicide ideation": imagining, invoking, playing, threatening, and staging suicide. Focusing ethnographically on such non-fatal suicidal action avoids, in Chua's words, "presumptive framings about intentionality, sincerity, destruction, and fatality" in the suicide analysis. Münster's ethnography also maintains analytical distance from the actuality of suicide cases and possible reasons for farmers' suicides, focusing instead on situated accounts - the various ways of writing and talking about the subject. He shows how the moral panic about such suicides becomes a productive idiom for farmers to rethink their agrarian practices. Sharp and Linos develop an 
anthropological understanding of Palestinian suicide bombings, yet another selfdestructive practice that, being notoriously difficult to frame as either pathology or anemia, is peripheral to the focus of suicidology - it is too violent against others, overtly tactical, and political. By focusing on suicide attacks, Sharp and Linos make a convincing case for widening our understanding of personhood within anthropologies of suicide to include the actual materiality of the person as a "corporeal entity."

Dwelling analytically at the boundaries of what people in general and scientists more specifically call suicide has proven to be productive for anthropology and related disciplines. Rane Willerslev (2009) presented the voluntary assisted death among Chukchi reindeer herders as a form of sacrifice that is locally perceived as categorically and morally distinct from suicide "proper." James Laidlaw (2005) pointed out the distinction drawn between voluntary fasting to death as a spiritual practice among Indian Jains and the same community's ridicule of "real" suicide as fool's death. Such works, together with the empirical material collected in this volume, suggest that questions about agency, which include issues of intentionality, knowledge, "voluntarism" (Osborne 2005), and responsibility, are central to the boundary work around the term suicide and hence for defining the object of study. In the following section, we elaborate on the logical tension of agency in scholarly, expert and lay engagements with suicide cases.

\section{The Tension of Agency: Denial, Necessity, and Ambivalence in Definitions of Suicide}

The International Statistical Classification of Diseases and Related Health Problems (ICD-10) issued by the World Health Organization lists "intentional self-harm" in the section titled "External Causes of Morbidity and Mortality." Hence the causes of intentional self-harm, which include suicide, are classified alongside assaults, traffic accidents and "complications of medical and surgical care," as external to the victim. Without wishing to labor this point, we believe that the categorical paradox epitomizes a more general tension between the requirement for agency and a simultaneous denial or diffusion of the agency of the suicidé in both popular and scientific understandings of suicide. This is at the same time a tension between two notions of the term "agency": intentionality and responsibility. Suicide categorically requires singular and undivided intention, yet cultural etiologies of suicide rarely attribute full responsibility to the agent. In suicide discourse, singular intention stands in tension with diffused responsibility. For modern understandings of suicide, the diffusion of agency is mediated via sociological and psychological approaches.

4 Available online at http://apps.who.int/classifications/icd10/browse/2010/en (accessed 30 March 2012). 
To develop our argument, we start by looking at the way suicidology defines its object of study. Emile Durkheim defined suicide as "all cases of death resulting directly or indirectly from a positive or negative act of the victim himself, which he knows will produce this result" (Durkheim 1952: xii; original emphasis replaced by our emphasis). One of the latest influential definitions of suicide, formulated by De Leo et al., considers it as "an act with fatal outcome, which the deceased, knowing or expecting a potentially fatal outcome, has initiated and carried out with the purpose of bringing about wanted changes" (2006: 12; our emphasis). The common denominator in these definitions is the agentive involvement of the suicidé, who is conceived as the sole author of his/her own death. In fact, the vast majority of suicide definitions formulated within suicidology are in this respect very similar. They identify the suicidé as the agent of the act "to distinguish between homicide and suicide" and invoke his/her intent, knowing, or comprehension to distinguish "between accidental and suicidal behavior" (Andriessen 2006: 534). The World Health Organization has even replaced the terms "suicide" and "suicide attempt" with "intentional self-harm" in its lexicon, which clearly highlights the centrality of intentional agency.

Intention and comprehension appear to be fundamental aspects of any definition of suicide, yet, for suicidologists, these are the features of the definition that are most difficult to operationalize. How can one ascertain the intentions of a deceased person? How can one deal with the multiplicity and sometimes contradictory nature of motives behind a single suicide act (Andriessen 2006; see De Leo et al. 2006)? What about suicidal acts in which "success" (mortality) depends on the ability or inability of another person to intervene in time? These questions become increasingly complex if we understand the self in certain contexts to be deeply relational rather than atomized. Yet, as some attempts at defining suicide without reference to intention or its equivalents have shown (cf. Egel 1999), the category of suicide becomes fuzzy and indistinguishable from that of accidents, murders, or the behavior of mentally ill individuals. Assessing the degree of human agency is central in determining causes of death, which in turn can be used to apportion legal and moral responsibility and blame of various kinds. In this respect, suicidology operates within the same logical framework as its nineteenth-century predecessors, not to mention the medieval courts whose distinction of an insane person not intending or comprehending the outcome of their own action (non compos mentis) from the sane one committing the conscious crime of self-murder (felo de se) (cf. Morrissey 2006: 41-2; Laragy 2013) seems likewise to rest on a notion of intentional agency.

Emerging statistical records of national suicide mortality rates in the nineteenth century laid the foundation for a contrary conceptualization of the problem of intentionality: the diffusion of individual agency in suicide. Ian Hacking summarized the problem thus:

Despite visible trends and perturbations in the short term, national suicide rates are remarkably stable. This was noticed at the very beginning of suicide statistics 
and led, in the 1850 s, to bizarre but very influential arguments that human beings do not have free will since the proportion of those who kill themselves, in a given population, is itself a law of social nature. (Hacking 2008: 8)

According to Hacking, such radical conclusions stemmed from the fact that suicide had previously been treated by some thinkers as the ultimate proof of human agency or free will. David Hume, for example, opined that "the one power that we have and that the gods lack is that we can kill ourselves" (paraphrased by Ian Hacking 2008: 4; see also Morrissey 2006: 3).

Later in the nineteenth century, Emile Durkheim drew a conceptual distinction between individual suicide cases on the one hand and suicide rates as a total social fact on the other. Even though he never arrived at any convincing "link between the way individual suicides are committed and social causation" (Gane 2005: 223), the overall message of his Le Suicide was nevertheless that "something as intimate as deciding to put an end to one's life results from the inflictions of others" (Vargas 2010: 209). This external other that ultimately causes suicide was for Durkheim "society" viewed as having an ontology of its own (Durkheim 1952: xiv). Thus, suicide was indicative not of the agency of the suicidé but of other processes or phenomena, such as the level of social integration of the victim. In effect, the intentional agency of the suicidé required by Durkheim's definition of suicide is undermined by his main explanatory achievement. Durkheim's "invention" of social constraint gave rise to the structure vs. agency dilemma in the social sciences, which could be seen as yet another version of theological debates about an omnipotent God and impotent humans or philosophical debates about free will and determinism.

The "thèse psychiatrique" also effectively diminishes the agency-asresponsibility of the suicidé by viewing any suicide as having been "caused" by mental illness or psychological disorder. Hence suicidal individuals became "positioned within this discourse of pathology as mentally unwell, and thus not fully responsible for their actions" (Marsh 2013: 749). The pathologizing "psy" discourses, which established individual suicide cases as indicative of the suicidé's medical condition rather than their agency, implied causes that, we argue, are "outside the person" as much as the sociological causes. Mental illness, just like the genes of which it is often said to be an effect (cf. Bondy et al. 2006; Mann et al. 2001), is conceptualized as part of one's body and identity but also as an entity external to it, for it is not limited to a single individual. Rather, genetically determined dispositions to illness are imagined as being passed from one generation to another, and in this sense they are extra-individual (Ingold 2000: 134-9). Furthermore, the (mental) illness is often spoken about as an entity distinct from the one who suffers from it, which is even recognized and utilized in some therapeutic approaches (Topf 1995).

In the process of secularizing the study of suicide, the emerging scientific disciplines of moral statistics and psychiatry have called into question the individual agency in the act (Morrissey 2006: 2). The consequences of this 
deflection of agency include both a de-criminalization and a de-politicization of suicide. Suicides ceased to be moral abominations but also ceased to be taken seriously as accusatory performances. The result of such changes is a tension of agency in suicide. The tension of agency is effective in popular and scholarly accounts of suicide whenever agency is deflected away from the suicidé towards sociological or psychological constraints (thus reducing the agent to the status of a victim), while simultaneously depending on an (at least implicit) notion of intentional agency in order to speak of suicide in the first place.

This volume offers a variety of examples of the tension of agency in suicide also from vernacular contexts. Broz (this volume), for instance, describes distributed agency in the context of a Siberian village, in which suicide is explained by a "soul-loss" prior to the suicidal act. The suicidé is thus rendered a victim, and their agentive involvement in the act is eroded to some degree. Reyes-Foster (this volume) describes a similar victimization of a suicidé in a Yucatec Maya village, where the act is attributed to the workings of the devil. Importantly, she observes convergences between these situated understandings of suicide and the biomedical discourse of mental illness imprinted in the state-sponsored suicide prevention program. She argues that the two interpretations proved surprisingly compatible because "the contradictory nature of the Yucatecan attitude toward suicide is a sympathetic template upon which biomedical discourse can map itself." It becomes evident from contributions in this volume, as well as from other ethnographies of suicide (e.g. Laidlaw 2005; Imberton 2012), that the tension of agency in suicide, as described above, is not specific to contemporary Western scientific discourses. Rather, it can be found in most situated attempts at making sense of suicide.

\section{Suicide and Personhood}

In the previous section we argued that the tension of agency, the dialectic of agency and patiency is intimately related to situated understandings of intentionality and responsibility in suicide. In this section we will expand on our argument about the simultaneous denial and attribution of agency in suicide discourse by suggesting that this tension is associated with diverse ideas about personhood that are often subscribed to simultaneously.

Theoretical advances in the social sciences and humanities have gradually "provincialized" (cf. Chakrabarty 2000) and destabilized Western conceptions of the bounded, unique human person as the only legitimate agent (Geertz 1974). Anthropologists have pointed out their anthropocentrism (Teubner 2006) and the more general Western "predilection for 'entities' and other static forms of being" (Course 2007: 21) and "bias toward singularity" (Callon and Law 1995: 499) when it comes to attribution of agency. Contemporary social theory has effectively reextended the franchise of agency to "non-humans" (to paraphrase Callon and Law 1995: 482), be they animals or material objects of various kinds (see e.g. Kirksey and Helmreich 2010; Latour 2005). 
In the light of data from non-Western socio-cultural contexts, human personhood has also been radically re-thought. For researchers following Marilyn Strathern's (1988) influential study, persons in Melanesia and elsewhere are, "not the repository of a unitary or bounded identity but rather composed of social relations, and in this sense [thinkable] as 'dividual' or 'partible' entities" (Carsten 2003: 94) . In other words, they are "inherently social." While numerous studies have demonstrated the theoretical appeal of such a conception of personhood, some have also challenged the dichotomy between Western "individual" and nonWestern "dividual," partible, or composite persons. In response to new phenomena (such as reproductive and prosthetic technologies) and refined ethnographic sensibilities, anthropologists argued that the assumption of individual personhood in the West may be little more than utopian phantasies of liberal philosophers (see Ouroussoff 1993) and have reconceptualized it, alongside other social theorists (Haraway 1991, 1997), as equally "joined-up," distributed, and relational (cf. Carsten 2003: 95-108).

These advances in social theory have had little impact on the study of suicide, regardless of the enthusiastic call for an anthropological imagination in suicidology (cf. Corin 1995; Kral 1998). Given the Western pedigree of suicidology, it is hardly surprising that it operates, as psychologist and ethnographer Michael Kral argues, with a "person-centered view of suicide" (1998: 229). ${ }^{5}$ This categorical dependence on specifically Western and liberal regime of the self leads researchers to ignore "the historical and cultural formation of ... suicidal subjects" and "the historical and cultural resources potentially able to counteract or resist suicide [as these] are seen to be of only marginal importance relative to the identification and treatment of individual mental disorders" (Marsh 2013: 749).

Many authors represented in this volume demonstrate the great potential of studying local conceptions of what it means to be a person and asking who else might be ascribed with agency in the suicide field. Persons and their others may contextually merge when humans are seen not as bounded subjects, whose behavior is influenced, shaped, or determined by social structures or bio-medical mechanisms, but as extended or distributed beyond the individual. Reyes-Foster, for example, speaks about the Mayan conception of personhood, in which "every person can extend into every other person that occupies the same place." Broz argues that in Altai (Siberia) domestic animals are a part of the personhood of their master and that they execute his or her agency. Many chapters also describe suicide fields in which important roles are given to entities, such as spirits or the devil, whose ontology must appear dubious from the perspective of Western suicidology.

5 We nevertheless disagree with Kral's assertion that for suicidology "the ultimate origin of suicide, whatever the stressful precursors, lies within the person" (1998: 229). Rather, the "person-centered" view stands for what we called above the "requirement of agency," while the "tension of agency" is created by the simultaneous placement of the origin of suicide outside the suicidé. 
Bringing local notions of personhood and agency into suicide studies once again raises questions about the universal applicability of the concept of suicide. If someone's death is understood locally as having been inflicted by, say, an evil spirit, can we still speak about the compatibility of such a notion of death with suicidology's category of suicide? How can one characterize acts of people that are seen locally as incomplete, de-composed? Are they agents of their own death, and can they commit suicide? We believe that, regardless of such important doubts, the category of suicide retains its comparative appeal. First, as we have argued above, vernacular distributions of intentionality and responsibility in suicide fields could share certain similarities with the tension of agency in academic suicidology. Such similarity makes many vernacular and expert understandings more compatible with each other than commonly thought and thus makes the ubiquitous tension of agency a good basis for a transcultural study of suicide. Second, a priori limitation of the category of suicide to western contexts would only lead to schematized "West vs. the rest" oppositions. As Staples (this volume) warns us, the dichotomization of Western and non-Western notions of a person could be misleading, not only because western notions of personhood are often relational, but also because various non-western theories of the suicide problem invoke assumptions about the boundedness of individuals. Moreover, in many contexts, as Staples demonstrates in his Indian ethnography, several notions of a person may be applied simultaneously:

Those engaged in suicide in India constitute themselves - and are constituted by others - both as individual agents who undertake unilateral acts intended, at the moment they occur, to result in particular outcomes; and as dispersed, fluid dividuals, where intent and consequences of a suicidal act are situated across a number of social agents - including parents and family members, spirits, and the evil eye. (Staples, this volume)

Drawing on Staples' argument, we suggest that at the heart of the "tension of agency in suicide" lie not only divergent yet concurrent notions of agency, as argued above, but also divergent yet simultaneously used notions of personhood. If a person is conceptualized as a unique individual and at the same time as a fluid dividual, he or she is then easily conceivable as being and simultaneously not being the sole author of his or her death. Such a perspective points to another aspect of the question of personhood and agency in suicide, namely, "personmaking" in the suicide field.

Suicidology generally assumes that the persons inhabiting the suicide fields exist prior to the act of suicide. While Jaworski (this volume) challenges this taken-for-granted premise from a Foucauldian, post-structuralist perspective, other authors do so by observing subjectivity and personhood in the making: they document the ways in which persons are contextually re-produced, often as immoral or moral, in their respective suicide fields. By doing so, they follow Ian Marsh's call to observe the "formation of particular kinds of 'suicidal subjectivities' in 
relation to the production and circulation of authoritative medical and psychiatric knowledge" (Marsh 2013: 751). Here the value added by anthropology lies in bringing examples of the formation of "suicidal subjectivities" from contexts characterized by very different views of morality and of (moral) personhood to the study of suicide and agency.

\section{Suicide and Power: Agency and Patiency}

Seen through the lens of power relations, acts of suicide are not only about death and dying but also about life and the living. Conventional suicidologies seem to privilege death and pathology as the problem space of suicide. Moral statistics logically begin with the counting of unambiguously dead bodies, whereas the "medical/psychiatric style of thought" (Marsh 2013: 747) operates closely within a "compulsory ontology of pathology," to use Ian Marsh's expression: "Suicide is formulated as pathological and individual, as tragic, and not to be read as in any way positive" (Marsh 2010: 47). Yet many suicidal acts, as Tom Widger (this volume) writes in his chapter on Sri Lanka, "are rarely concerned with dying but seeking new ways of living." In terms of ontology, many of the ethnographies assembled here place suicide in life rather than in death and pathology; they explore ways of living with suicide and the productivity of suicide in fields of power. The capacity of the living to do things with suicide is best captured by a classical notion of agency that refers to spaces of freedom and the human capacity to act within structures of power. The anthropology of suicide articulates with foundational anthropological questions about domination and resistance, hegemony and freedom, power and authorship (see Jaworski this volume). At the same time, the politics of suicide displays the same tension of agency - its dialectical denial and overemphasis - that is so ubiquitous in most suicide discourses. Anthropological engagements with the articulation of suicide and power are simultaneously anthropologies of agency and patiency, free will and victimhood, and sovereignty and bare life (Agamben 1998).

Anthropological studies of suicide have pointed to the accusation inherent in most suicidal attempts and successful suicides, even those related to issues of "domestic justice" (Wu 2010). The question, then, is who is accused (implicitly or otherwise) through the suicidal act? Does the rage of the suicidal violence speak to the suicidé's immediate livelihood circumstances, does it reach to the local exploiter/violator, or is it an indictment of the larger structural violence of politics and political economy (see Farmer 2003)? Anthropological theorizing on suicide, beginning with Malinowski (1978 [1926]) and Firth (1961), seems to agree that most suicides entail elements of accusation or revenge or of an indictment against wrongdoers in kinship affairs, and that suicides are ultimately communicative acts and have, in Anthony Giddens' words, a "social aetiology" (Giddens 1964, 1977).

Beyond the implicit micro politics of most suicides, anthropologists deal with explicitly political suicides (Andriolo 2002, 2006; Feldman 1991) and stress that these suicides have a message and that it is their strategic objective, as Karin 
Andriolo argues, to get that message across to whoever/whatever is responsible for the "wrong of moral, political, or economic dimension, a wrong that affects the lives of many" (2006: 102). She understands protest suicides as "embodied minding," the quite literal inscription of a political message onto the body of the protester: "Protest suicide is dying with a message, for a message, and of a message. The body becomes the site on which self-destructive mimesis denounces the wrongs that humans have wrought" (Andriolo 2006: 102). Sharp and Linos (this volume) move beyond such a communicative model of protest suicide, by considering the role of body parts in the tactical employment of suicide bombing by Palestinian combatants. One could argue that there is no message inscribed into these bodies, but that the blood, organs, and other body parts of the suicide attacker are themselves a necro-political pollutant with the potency to re-classify space as Palestinian instead of Israeli.

Many authors in this volume take a different approach to political agency in suicide to that followed by Andriolo, who clearly distinguishes protest suicides with clear-cut messages and political authorship — such as the deaths of hunger strikers in Northern Ireland, South Asian self-immolations, and the case of the South Korean farmer-activist who stabbed himself at the World Trade Organization's Cancún summit-from "regular" suicides with their histories of personal and psychological "suicidality." Instead, they examine the political content in "suicidality." The challenge, we argue, is not to distinguish political from pathological suicides, but rather to move beyond voluntaristic understandings of self-destruction, which would require an autonomous will on the part of the suicidé to count as political. The ethnographies in this volume examine how less spectacular suicides (compared to public protest suicides) by young people (Staples this volume), indebted farmers (Münster this volume), or older women (Chua this volume) may function as political acts, indictments against structures of constraint, or performances of "J'accuse" in the face of power, or how even quotidian suicide can create, as Widger (this volume) puts it, "opportunities for social and moral action and commentary."

Ethnographic attention to power and the political does not necessarily grant agency to the suicidé. A focus on the role of structural violence (Farmer 2004) and resistance may render the suicide just another "reflection" of political economic changes beyond the control of the individual. From this perspective, crises, transformations, and the violence of structures and organizations, as well as bad relationships of any sort, are too easily understood as "driving" the person to suicide. The agency of the suicidé is reduced to victimhood; their death ultimately becomes an effect of power. In considering suicide and power, there is thus a thin line between a denial of and an overemphasis of agency.

In making suicide the object of study, critically realist ethnographies of the contemporary human condition will have to engage with the epistemological challenge of adequately appreciating the diagnostic qualities of suicide. What do we learn about contemporary life and the effects of power on populations by studying suicide? Does the study of suicide provide ethnographers with a diagnostic 
tool for detecting "pathologies of power" (Farmer 2003) and the necro-politics of global capitalism? Anthropologists will have to demonstrate how suicide can tell us better than other forms of human action about the central concerns of our times and about how people dwell in the contemporary world. The contributions to this volume, we believe, demonstrate the richness of the new perspectives that can be gained by studying fields of suicide, power, and agency.

\section{Conclusion}

In this introduction we have argued that most academic and vernacular notions of suicide are predicated on the agentive involvement of the suicidé. We have further demonstrated that both vernacular and scientific attempts to make sense of suicide simultaneously undermine or distribute the agency of the suicidé - their sole authorship of the act-which leads to what we call the tension of agency in suicide. Ethnographic approaches to studying suicide, which most authors of this volume employ and advocate, do not overcome this tension of agency. On the contrary, as pointed out above, they create a similar kind of tension: most ethnographic studies treat suicides both as expressions of individual choice and as indicators of pathologies of power and larger structural constellations.

The lesson we draw from the works collected in this volume is that aiming to resolve the tension of agency in suicide is pointless. Instead, we suggest focusing anthropological attention on the study of how this tension plays out in particular vernacular and scientific contexts and, using the reflexive faculty of anthropology, how it becomes manifest in our own analysis. The tension of agency in suicide points to a continuum of causality and responsibility, ranging from the sole authorship of the suicidé to plain victimhood of the suicidé subjected to external forces (social, chemical, invisible). The positioning of particular acts of self-destruction along this continuum is dialectically connected to the moral evaluation of suicide in particular contexts. On the one hand, convictions about the $\mathrm{im} /$ morality of suicide determine the un/ease with which the agentive involvement of the suicidé and even the categorization of particular deaths as suicide could be reinterpreted. On the other hand, ideas about suicidé's agentive involvement in the act often determine local moral classification of suicide as a category. When people contest interpretations of particular suicides, they could be understood as rhetorically moving the case along the continuum and shifting emphasis between different and yet simultaneously used notions of personhood and agency. If someone is conceptualized as a unique individual and at the same time as a fluid dividual, they are then easily conceived as being and simultaneously not being the sole author of their death, depending on which understanding of the person is contextually stressed.

The authors of this volume see situated efforts to make sense of suicide as being predicated on specific notions of agency, intentionality, subjectivity, and personhood. In this sense, the anthropology of suicide, just like the dominant 
"psychologizing" and "sociologizing" approaches, sees suicide as indicative of complex concerns. The reflexive enterprise of anthropology nevertheless aims at non-reductionist ways of understanding the indicative dimension of suicide. Even when treating particular suicide fields as indicative of local notions of agency, personhood, or intentionality, suicide is never reduced to such notions; rather, these notions help us, in a manner of mutual explication, to better comprehend local ontologies of suicide.

We remain skeptical about a universal definition of suicide and, instead, work towards an anthropological notion of suicide by comparatively engaging with varieties of self-destructive action and their contested interpretations. Hence, the category of suicide is employed in this volume as a fluid heuristic tool, a provisional agreement about the subject of series of disagreements generated in each particular ethnographic setting, regardless of whether it stands for popular or authoritative knowledge. Such symmetrical treatment of different kinds of knowledge about suicide supports the overall claim of this volume, namely that the category of suicide is almost universally intertwined with particular notions of agency and personhood and with the connected tension of agency in suicide.

\section{References}

Agamben, G. 1998. Homo sacer: sovereign power and bare life. Stanford, CA: Stanford University Press.

Andriessen, K. 2006. On 'intention' in the definition of suicide. Suicide \& LifeThreatening Behavior 36, 533-8.

Andriolo, K. 2002. Murder by suicide: episodes from Muslim history. American Anthropologist 104, 736-42.

2006. The twice-killed: imagining protest suicide. American Anthropologist $108,100-113$.

Bloch, M. and J.P. Parry 1982. Introduction: death and the regeneration of life. In Death and the regeneration of life (eds) M. Bloch and J.P. Parry, 1-44. Cambridge: Cambridge University Press.

Bohannan, P. 1960. African homicide and suicide. Princeton, NJ: Princeton University Press.

Bondy, B., A. Buettner and P. Zill 2006. Genetics of suicide. Molecular Psychiatry 11, 336-51.

Callon, M. and J. Law 1995. Agency and the hybrid collectif. The South Atlantic Quarterly 94, 481-507.

Camus, A. 1955. The myth of Sisyphus. Penguin.

Carsten, J. 2003. After kinship. Cambridge: Cambridge University Press.

Chakrabarty, D. 2000. Provincializing Europe: postcolonial thought and historical difference. Princeton, NJ: Princeton University Press.

Corin, E. 1995. From a cultural stance: suicide and aging in a changing world. International Psychogeriatrics 7, 335-55. 
Course, M. 2007. Death, biography, and the Mapuche person. Ethnos 72, 77-101. Douglas, J.D. 1967. The social meanings of suicide. Princeton, NJ: Princeton University Press.

Dowsett, S. 2012. Spain suspends home evictions for most needy. Reuters, 15 November (available online: http://www.reuters.com/article/2012/11/15/usspain-evictions-idUSBRE8AE10A20121115, accessed 27 July 2013).

Durkheim, E. 1952. Suicide, a study in sociology. London: Routledge and K. Paul. Egel, L. 1999. On the need for a new term for suicide. Suicide and Life-Threatening Behavior 29, 393-4.

Farmer, P. 2003. Pathologies of power: health, human rights, and the new war on the poor. Berkeley: University of California Press.

2004. An anthropology of structural violence. Current Anthropology 45, 305-25.

Feldman, A. 1991. Formations of violence: the narrative of the body and political terror in Northern Ireland. Chicago: University of Chicago Press.

Firth, R. 1961. Suicide and risk-taking in Tikopia society. Psychiatry: Journal for the Study of Interpersonal Processes 24, 1-17.

Gane, M. 2005. Durkheim's scenography of suicide. Economy and Society 34, 223-40.

Geertz, C. 1974. 'From the native's point of view': on the nature of anthropological understanding. Bulletin of the American Academy of Arts and Sciences $28,26-45$.

Gibbs, N. and M. Thompson 2012. The war on suicide? Time, 23 July (available online: http://www.time.com/time/magazine/article/0,9171,2119337,00.html).

Giddens, A. 1964. Suicide, attempted suicide, and the suicidal threat. Man 64, 115-16.

- 1977. A theory of suicide. In Studies in social and political theory, 297-332. New York: Basic Books.

Hacking, I. 1990. The taming of chance. Cambridge: Cambridge University Press. 2008. The suicide weapon. Critical Inquiry 35, 1-32.

Haraway, D.J. 1991. Simians, cyborgs, and women: the reinvention of nature. London: Free Association Books.

_ 1997. Modest_Witness@Second_Millennium.FemaleMan $\mathbb{C}$ Meets_Onco Mouse ${ }^{\mathrm{TM}}$. Feminism and Technoscience. London and New York: Routledge.

Houston, R. 2009. The medicalization of suicide: medicine and the law in Scotland and England, circa 1750-1850. In Histories of suicide: international perspectives on self-destruction in the modern world (eds) J. Weaver and D. Wright, 91-118. Toronto: University of Toronto Press.

Imberton, G. 2012. Chol understandings of suicide and human agency. Culture, Medicine, and Psychiatry 36, 245-63.

Ingold, T. 2000. The perception of the environment: essays on livelihood, dwelling and skill. London and New York: Routledge.

Kirksey, S.E. and S. Helmreich 2010. The emergence of multispecies ethnography. Cultural Anthropology 25, 545-76. 
Kral, M.J. 1998. Suicide and the internalization of culture: three questions. Transcultural Psychiatry 35, 221-33.

Laidlaw, J. 2005. A life worth leaving: fasting to death as telos of a Jain religious life. Economy and Society 34, 178-99.

Laragy, G. 2013. 'A peculiar species of felony': suicide, medicine, and the law in Victorian Britain and Ireland. Journal of Social History 46, 732-43.

Latour, B. 2005. Reassembling the social: an introduction to actor-networktheory. Oxford: Oxford University Press.

De Leo, D., S. Burgis, J.M. Bertolote, A.J.F.M. Kerkhof and U. Bille-Brahe 2006. Definitions of suicidal behavior. Crisis: The Journal of Crisis Intervention and Suicide Prevention 27, 4-15.

Li, T.M. 2007. The will to improve: governmentality, development, and the practice of politics. Durham, NC: Duke University Press.

Macdonald, C.J.-H. 2007. Uncultural behavior: an anthropological investigation of suicide in the southern Philippines. Honolulu: University of Hawaii Press.

Malinowski, B. 1978. Crime and custom in savage society. London: Routledge and Kegan Paul.

Mann, J.J., D.A. Brent and V. Arango 2001. The neurobiology and genetics of suicide and attempted suicide: a focus on the serotonergic system. Neuropsychopharmacology 24, 467-77.

Marks, A. 2003. Historical suicide. In Handbook of death and dying (ed) C.D. Bryant, 308-18. London: Sage.

Marsh, I. 2010. Suicide: Foucault, history and truth. Cambridge: Cambridge University Press.

2013. The uses of history in the unmaking of modern suicide. Journal of Social History 46, 744-56.

Menninger, K. 1938. Man against himself. New York: Harcourt, Brace and World, Inc.

Morrissey, S.K. 2006. Suicide and the body politic in Imperial Russia. Cambridge: Cambridge University Press.

Münster, D. 2012. Farmers' suicides and the state in India: conceptual and ethnographic notes from Wayanad, Kerala. Contributions to Indian Sociology 46, 181-208.

Osborne, T. 2005. 'Fascinated dispossession': suicide and the aesthetics of freedom. Economy and Society 34(2), 280-94.

Ouroussoff, A. 1993. Illusions of rationality: false premisses of the liberal tradition. Man 28, 281-98.

Rabinow, P. 1986. Representations are social facts. Modernity and post-modernity in anthropology. In Writing culture: the poetics and politics of ethnography (eds) J. Clifford and G. Marcus, 234-61. Berkeley: University of California Press.

Range, L.M. and M.M. Leach 1998. Gender, culture, and suicidal behavior: a feminist critique of theories and research. Suicide and Life-threatening Behavior 28, 24-36. 
Rose, N. 1998. Inventing our selves: psychology, power, and personhood. Cambridge: Cambridge University Press.

2006. The politics of life itself: biomedicine, power, and subjectivity in the twenty-first century. Princeton, NJ: Princeton University Press.

Schnepel, B. 2009. Zur Dialektik von Agency und Patiency. Paragrana. Internationale Zeitschrift für Historische Anthropologie 18, 15-22.

Seale, C. and S. van der Geest 2004. Good and bad death: introduction. Social Science and Medicine 58, 883-5.

Shneidman, E.S. 2001. Comprehending suicide: landmarks in 20th-century suicidology. Washington, DC: American Psychological Association.

Staples, J. and T. Widger 2012. Situating suicide as an anthropological problem: ethnographic approaches to understanding self-harm and self-inflicted death. Culture, Medicine, and Psychiatry 36, 183-203.

Strathern, M. 1988. The gender of the gift: problems with women and problems with society in Melanesia. Berkeley: University of California Press.

Teubner, G. 2006. Rights of non-humans? Electronic agents and animals as new actors in politics and law. Journal of Law and Society 33, 497-521.

Topf, L. 1995. You are not your illness: seven principles for meeting the challenge. New York: Simon and Schuster.

Vargas, E.V. 2010. Tarde on drugs, or measures against suicide. In The social after Gabriel Tarde (ed) M. Candea, 208-29. London: Routledge.

Waidzunas, T. 2011. Young, gay, and suicidal: dynamic nominalism and the process of defining a social problem with statistics. Science, Technology and Human Values 37, 199-225.

Weaver, J. and D. Wright 2009. Histories of suicide: international perspectives on self-destruction in the modern world. Toronto: University of Toronto Press.

Willerslev, R. 2009. The optimal sacrifice: a study of voluntary death among the Siberian Chukchi. American Ethnologist 36, 693-704.

Wu, F. 2010. Suicide and justice: a Chinese perspective. London and New York: Routledge. 


\title{
Suicide and Agency \\ Anthropological Perspectives on Self-Destruction, Personhood, and Power
}

\author{
Edited by \\ LUDEK BROZ \\ and \\ DANIEL MÜNSTER
}


All rights reserved. No part of this publication may be reproduced, stored in a retrieval system or transmitted in any form or by any means, electronic, mechanical, photocopying, recording or otherwise without the prior permission of the publisher.

Ludek Broz and Daniel Münster have asserted their right under the Copyright, Designs and Patents Act, 1988, to be identified as the editors of this work.

Published by

Ashgate Publishing Limited

Ashgate Publishing Company

Wey Court East

110 Cherry Street

Union Road

Suite 3-1

Farnham

Burlington, VT 05401-3818

Surrey, GU9 7PT

USA

England

www.ashgate.com

\section{British Library Cataloguing in Publication Data}

A catalogue record for this book is available from the British Library

The Library of Congress has cataloged the printed edition as follows:

Suicide and agency : anthropological perspectives on self-destruction, personhood and power / edited by Ludek Broz and Daniel Münster.

pages $\mathrm{cm}$.- (Studies in death, materiality and the origin of time)

Includes bibliographical references and index.

ISBN 978-1-4724-5791-2 (hardback) - ISBN 978-1-4724-5792-9 (ebook)—ISBN 978-

1-4724-5793-6 (epub) 1. Suicide-Sociological aspects. 2. Agent (Philosophy) I. Broz, Ludek, 1975- editor. II. Münster, Daniel, 1973- editor.

HV6545.S8194 2015

$362.28-\mathrm{dc} 23$

2015016069

ISBN: 9781472457912 (hbk)

ISBN: 9781472457929 (ebk - PDF)

ISBN: 9781472457936 (ebk - ePUB)

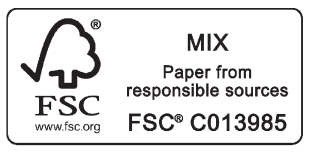

Printed in the United Kingdom by Henry Ling Limited, at the Dorset Press, Dorchester, DT1 1HD 


\section{Contents}

List of Figures

vii

Notes on Contributors ix

Acknowledgments xiii

\section{PART I INTRODUCTION}

1 The Anthropology of Suicide: Ethnography and the Tension of Agency

Daniel Münster and Ludek Broz

\section{PART II SUICIDE, PERSONHOOD AND RELATIONALITY}

2 Personhood, Agency and Suicide in a Neo-Liberalizing South India

James Staples

3 The Lonely Un-Dead and Returning Suicide in Northwest Greenland

Janne Flora

4 Between Demons and Disease: Suicide and Agency in Yucatan, Mexico

Beatriz M. Reyes-Foster

$5 \quad$ Four Funerals and a Wedding: Suicide, Sacrifice, and (Non-)Human Agency in a Siberian Village

Ludek Broz

PART III SELF-DESTRUCTION AND POWER: BODIES, RESISTANCE AND CRISES

6 Farmers' Suicide and the Moral Economy of Agriculture:

Victimhood, Voice, and Agro-Environmental Responsibility in South India

Daniel Münster 
$7 \quad$ Dying to Live in Palestine: Steadfastness, Pollution and Embodied Space

Deen Sharp and Natalia Linos

8 Accumulating Death: Women's Moral Agency and Domestic Economies of Care in South India

Jocelyn Chua

9 Learning Suicide and the Limits of Agency: Children's

"Suicide Play" in Sri Lanka

Tom Widger

10 Suicide, Agency and the Limits of Power

Katrina Jaworski

\section{PART IV AFTERWORD}

11 Afterword: Taking Relationality to Extremes

Marilyn Strathern

Index 